\title{
Qual foi o papel das variáveis midiáticas na eleição presidencial de 2010?
}

\author{
\begin{tabular}{c}
\hline \hline Heloisa Dias Bezerra \\
Universidade Federal de Goiás \\
Faculdade de Ciências Sociais \\
Pedro Santos Mundim \\
Universidade Federal de Goiás \\
Faculdade de Ciências Sociais \\
\hline \hline
\end{tabular}
}

Resumo: Neste artigo apresentamos os resultados de um estudo preliminar sobre os efeitos de variáveis midiáticas no processo de decisão do voto dos brasileiros para a eleição presidencial de 2010. Os resultados de modelos logísticos multinomiais estimados com os dados do ESEB 2010 sugerem que duas das cinco variáveis midiáticas utilizadas - debates e atenção política - influenciaram o voto dos eleitores a favor de Serra, e contra Dilma, respectivamente no $1^{\circ}$ e no $2^{\circ}$ turnos da eleição. Ao mesmo tempo, outras duas variáveis apresentaram resultados contra intuitivos: a maior exposição aos jornais impressos e ao programa Brasil Urgente aumentavam a probabilidade de o eleitor preferir abster-se, votar em branco ou nulo do que votar em Dilma. Ainda que esta seja uma análise inicial, esses resultados estão mais em sintonia com as visões que defendem um papel mais ativo da mídia durante as eleições do que com aquelas que defendem a sua irrelevância.

Palavras-chave: Meios de Comunicação de Massa, Efeitos da Mídia, Voto, Eleição Presidencial de 2010, CSES-ESEB 2010.

\begin{abstract}
:
In this article we present the results of a preliminary study about the effects of media variables on the voting decision process at the 2010 presidential election. The results from logistic multinomial models estimated with ESEB 2010's data suggest that two of the five variable used here - debates and political awareness - influenced the voters' decision in favor of Serra and against Dilma respectively in the first and second rounds. At the same time two other variables presented counterintuitive results: a greater exposition to traditional press and to the program Brasil Urgente increased the probability on part of the electorate to defect or to cast blank and spoiled votes instead of voting on Dilma. Even though this is an initial analysis, the results are closer to the visions that defend a more active role for the media during the elections than with those visions that call for the media's irrelevance.
\end{abstract}

Keywords: Mass Media, Media Effects, Voting, Presidential Elections of 2010, CSES-ESEB 2010. 
BEZERRA, H. D.; MUNDIM, P. S. Qual foi o papel das variáveis midiáticas na eleição...

\section{Introdução}

É comum, ao fim de cada eleição, que analistas e cientistas políticos busquem explicar os resultados das urnas e as razões do voto dos eleitores, e que dessas explicações, muitas vezes, surjam importantes e prolongados debates. Da eleição de 2006, que reelegeu Lula (PT) presidente, podemos citar dois exemplos: o que foi mais importante para a reeleição, a economia ou o programa Bolsa Família (NICOLAU E PEIXOTO, 2007; CARRARO et al, 2007; CÂNEDO-PINHEIRO, 2009)? E qual o significado político do processo que levou à "mudança da base social do voto em Lula" (SOARES e TERRON, 2008): a emergência de uma tardia "luta de classes" no Brasil (AMARAL, 2006), ou a demonstração de uma racionalidade estratégica dos eleitores (ZUCCO, 2008)?

O mesmo pode ser dito das discussões sobre a cobertura da imprensa na eleição de 2006, ainda que o debate existente seja de menor proporção. O fato de Lula ter sido reeleito presidente, com mais de $60 \%$ dos votos válidos, mesmo após uma cobertura bastante negativa dos principais veículos de informação do país em relação à sua candidatura e ao seu governo, levou diversos pesquisadores e analistas a celebrarem a "derrota da imprensa", sua irrelevância para o resultado final no pleito e a derrocada das teorias da opinião pública (COIMBRA, 2007; KUCINSKI, 2007; RUBIM, 2007). Outros trabalhos, contudo, encontraram evidências de um papel mais ativo da cobertura da imprensa em momentos importantes da disputa e para as mudanças na configuração das bases eleitorais, da situação e da oposição, entre 2002 e 2006 (MUNDIM 2010, 2011).

O ESEB 2006 não trouxe variáveis midiáticas que nos permitissem analisar o papel desempenhado pelos meios de comunicação e produtos midiáticos no processo de decisão do voto dos eleitores, o que provavelmente teria sido de grande valia para o aprofundamento e o esclarecimento das divergências mencionadas acima. Na coleção ESEB, apenas as ondas realizadas em 2002 e 2010 incorporaram ao seu núcleo temático perguntas midiáticas, o que nos permitiu examinar o papel que a mídia desempenhou nesta última eleição presidencial ${ }^{1}$.

Neste artigo trabalhamos com o banco de dados do ESEB 2010, utilizando variáveis midiáticas, políticas, econômicas e sociodemográficas. Na primeira parte do texto discutimos porque os meios de comunicação, mesmo os mais tradicionais e com o crescimento do uso da Internet, continuam a desempenhar um papel fundamental na política e nas eleições. Em seguida, apresentamos as hipóteses do

1 Neste artigo, o termo mídia será utilizado de um modo amplo para se referir tanto aos meios de informação tradicionais, os programas de soft news e os debates entre os presidenciáveis, quanto para um indicador da exposição dos eleitores ao fluxo de informações políticas produzidas durante a campanha. 
trabalho, sendo a principal delas que os efeitos das variáveis midiáticas, especialmente as ligadas à cobertura da imprensa, foram mais favoráveis à oposição do que à situação em 2010. Finalmente, apresentamos os resultados da nossa análise empírica.

Os resultados de modelos logísticos multinomiais estimados com os dados do ESEB 2010 sugerem que, de fato, duas das cinco variáveis midiáticas utilizadas - debates e atenção política - influenciaram o voto dos eleitores a favor de Serra, e contra a Dilma, respectivamente no $1^{\circ}$ e no $2^{\circ}$ turnos da eleição. Ao mesmo tempo, outras duas variáveis apresentaram resultados, até certo ponto, contra intuitivos: a maior exposição aos jornais impressos e ao programa Brasil Urgente aumentavam a probabilidade de o eleitor preferir abster-se, votar em branco ou nulo, do que votar em Dilma. Ainda que esta seja uma análise inicial, esses resultados estão mais em sintonia com as visões que defendem um papel mais ativo da mídia durante as eleições, do que com aquelas que defendem a sua irrelevância.

\section{Emissão midiática e efeitos sobre a formação da opinião}

Duas décadas se passaram desde 1989, ano que marcou o retorno das eleições livres e diretas para a presidência do Brasil. Nesse período, vimos Lula sair derrotado em três eleições consecutivas. Contudo, a roda da história girou. Entre 2002 a 2010 o petista foi eleito duas vezes para a presidência da República, com vitórias expressivas, e fez de Dilma Rousseff (PT) a sua sucessora e a primeira presidenta do Brasil.

Mas, a cada eleição, os analistas continuaram fazendo-se as mesmas perguntas: qual o impacto dos noticiosos nas campanhas eleitorais? O que é e para que serve uma notícia positiva ou negativa? Num país com cerca de 126 milhões de eleitores, um veículo de comunicação sozinho tem poder suficiente para mobilizar as elites, influir no voto dos eleitores e assim decidir os rumos de uma eleição? E os eleitores, a quais níveis de exposição midiática se submetem em cada pleito eleitoral? Que níveis de exposição são mais deletérios em relação a formação da opinião eleitoral?

No Brasil, a relação entre mídia e política desperta amor e ódio, especialmente nos anos eleitorais. Em muitos casos, os próprios jornalistas trazem à tona eventos escabrosos e opiniões apaixonadas envolvendo a postura do jornalismo político de alguns colegas e veículos (NASSIF, 2007; VIANNA, 2007; KAMEL, 2007). Boa parte das manifestações e mesmo dos estudos sobre a interferência da mídia no processo eleitoral tratam do tema na fronteira entre a indignação e a defesa enfática da liberdade de expressão. É difícil provar se há ou não intenção da mídia, ou melhor, dos veículos de comunicação, de ajudar ou 
BEZERRA, H. D.; MUNDIM, P. S. Qual foi o papel das variáveis midiáticas na eleição...

atrapalhar determinados candidatos. É preciso uma boa metodologia de pesquisa e a definição certeira dos problemas a serem analisados.

Certo mesmo é que a comunidade científica não dispõe de mecanismos definitivos para medir os efeitos da emissão midiática sobre a formação da opinião política, que é o que realmente importa, e conseqüentemente sobre a decisão do voto. Daí as diversas leituras, muitas vezes contraditórias, que podem surgir acerca do processo de formação de uma maioria capaz de eleger ou derrotar uma candidatura. São armadilhas analíticas complexas, que podem ser desdobradas em três ordens de problemas:

1) do olhar a posteriori do analista sobre o processo eleitoral e que, freqüentemente, resulta em induções sobre o efeito midiático segundo a lógica do resultado obtido pelo vencedor;

2) da impossibilidade de destrinchar a memória do eleitor e, portanto, de saber em que momento exato foi tocado por um fragmento informacional significativo e das suas reações e interações a partir desta(s) ocorrência(s);

3) da suposição de uma mídia homogênea nos seus interesses mais gerais e imediatos durante a cobertura das campanhas, o que poderia resultar em um discurso midiático único e linear em favor de um candidato.

De acordo com alguns estudos, os veículos de comunicação tratam as competições eleitorais de modo muito semelhante a outras notícias, com destaque para o drama, os escândalos, a formação de pares antagônicos/adversários e as "fofocas" (SCHUDSON, 1995; CURRAN, 1996; PATTERSON, 1993). O modo como as notícias são construídas e divulgadas também pode influir no seu consumo final. Em alguns casos, a informação política principal é apresentada sob acessórios tão intrincados que podem dificultar a compreensão dos eventos políticos; noutros casos, a repetição de uma mesma história é tamanha, especialmente envolvendo escândalos, que os olhos e ouvidos do leitor/telespectador podem se tornar refratários àquele assunto. Ainda assim, especialistas apontam os meios de comunicação como um dos fatores principais no processo de informação que, em algum momento, incidirá sobre a opinião individual, transformando-a (POPKIN, 1994; PAGE E SHAPIRO E DEMPSEY, 1987; MAIER, 2011).

$O$ ponto de vista dos candidatos também deve ser considerado. Afinal, no atual estágio de desenvolvimento das campanhas eleitorais é inconteste a necessidade de se usar meios capazes de replicar em massa um discurso, uma idéia, uma imagem. Para Manin (2005), a "democracia do público" torna imperativo 
que os candidatos assumam o papel de protagonistas das candidaturas para além dos partidos políticos, personalizando a política e aproximando o eleitor de uma dimensão humana e não técnica da campanha.

A Internet ampliou este leque de possibilidades conceituadas na "democracia do público" para além da figura dos candidatos, já que permite às equipes de marketing trabalharem com estratégias de emocionalização diferenciadas, tais como o chamado marketing viral, o qual, resumidamente, consiste no uso de técnicas de replicação desenfreada de uma mensagem utilizando, para tal, os próprios consumidores dessa mensagem. Ao receber uma mensagem o internauta, "emocionalmente contaminado", vai repassá-la imediatamente para sua rede de contatos e, principalmente, vai organizar uma série de ações com o objetivo de reforçar sua atitude, sua preferência. As redes sociais permitem que os próprios eleitores, militantes ou não, atuem como replicadores em massa. Com isto, o papel de protagonista que cabia exclusivamente ao candidato passa a ser partilhado com os internautas.

Ainda é cedo para fazer grandes afirmações sobre os efeitos da Internet na opinião do eleitor, mas o sucesso da estratégia de campanha implementada pela equipe de Barack Obama, em 2008, reforça, no mínimo, a necessidade de estudos mais aprofundados sobre o tema ${ }^{2}$. E o papel das equipes de campanha passa a ir além da simples criação da propaganda que, por exemplo, vai ser veiculada no HGPE. Estratégias de ataque e defesa frente ao que é produzido pelos veículos noticiosos ganham importância, já que o espaço para veiculação agora é ilimitado.

Neste contexto, o próprio modelo proposto por Lazarsfeld, Berelson e Gaudet (1948 [1944]), conhecido como "fluxo de comunicações em duas etapas", pode ser repensado e servir como parâmetro para um novo entendimento do poder dos meios. Com o crescimento do número de internautas e a possibilidade de uso desenfreado das redes sociais e de telefones móveis, os indivíduos passam a condição inevitável de produtores de conteúdo. A influência do formador de opinião clássico, mediante o uso dos aplicativos tecnológicos, é partilhada com um número crescente de replicadores de informação.

Na política cotidiana as novas mídias também chamam a atenção pelo uso feito por cidadãos comuns. Em 2011, os eventos ocorridos na "Primavera Árabe"3 demonstraram a força das redes sociais, não apenas por meio dos aplicativos tecnológicos disponíveis na Internet, mas também com o uso de telefones celulares

2 Infelizmente, o ESEB 2010 não trouxe variáveis sobre consumo de informações políticas via Internet e uso de aplicativos tecnológicos para intercomunicação pessoal durante a campanha presidencial de 2010. Portanto, uma análise sobre este tópico não será feita aqui.

3 Onda de protestos no Oriente Médio e norte da África que resultou na queda de regimes ditatoriais de longa década. 
BEZERRA, H. D.; MUNDIM, P. S. Qual foi o papel das variáveis midiáticas na eleição...

para envio de mensagens SMS e, principalmente, para captação de imagens e postagem das mesmas na grande rede mundial de computadores. Durante alguns confrontos, a mídia tradicional não podia captar imagens para a televisão e usou, em grande medida, as imagens feitas pelos cidadãos locais. Para Silveira (2007), as novas mídias podem ser pensadas como organizadores coletivos da atuação política do cidadão comum.

O importante, neste caso, é termos claro que ao analisar o impacto da mídia não podemos supor que o eleitor está sujeito à opinião de um único veículo de informação, mas a um fluxo comunicacional que vai além das mídias tradicionais e que passa, certamente, pela comunicação interpessoal.

Isso não quer dizer que as mídias tradicionais perderam o posto de mais influentes. Ao contrário, tanto os meios impressos quanto os eletrônicos estão antenados com o impacto das novas mídias sobre o consumo dos usuários e, rapidamente, estão convergindo para as novas tecnologias. Isto significa que, ao responder a perguntas do tipo "Quantos dias por semana o Sr.[a] lê jornal?" as respostas podem ser enviesadas (conforme discutiremos melhor abaixo) também pelo fato de não termos controle sobre se o respondente leu diretamente o noticioso ou se teve acesso a algum fragmento informacional, oriundo do meio impresso, via Internet, celular ou mediado por algum contato de sua rede social. Isto reforça nosso investimento analítico sobre um índice de atenção midiática, o qual acreditamos tem um poder explicativo significativo se comparado a análise tópica de exposição e recepção.

\section{Hipóteses e descrição das variáveis}

As análises feitas nesse artigo concentram-se, principalmente, nos dados obtidos sobre a eleição presidencial de 2010. Contudo, uma comparação com 2006 é inevitável, pois entendemos que muitos dos fatores que ajudaram Lula a se reeleger, como a sua popularidade e o estado favorável da economia do país, afetaram o comportamento dos eleitores a favor de Dilma. Ao mesmo tempo, podemos esperar que algo semelhante tenha ocorrido com alguns fatores que the foram desfavoráveis.

Por esses motivos, a nossa análise poderia partir de duas hipóteses: que os efeitos das variáveis midiáticas, especialmente as ligadas à cobertura da imprensa, foram mais favoráveis à oposição do que à situação em 2010; e que a avaliação do governo Lula, do estado da economia, além da preferência partidária, fatores importantes para a reeleição do petista, foram fundamentais para a vitória de Dilma, seja dando-Ihe votos, seja servido-Ihe como mecanismos de resistência capazes de amenizar ou diluir os efeitos das variáveis midiáticas. Ambas as 
situações ocorreram em 2006 (MUNDIM, 2010).

A nossa segunda hipótese é simples e está de acordo com estudos clássicos sobre as razões do voto, formação da opinião pública e efeitos da mídia (LAZARSFELD, BERELSON e GAUDET, 1948 [1944]; CONVERSE 1964; ZALLER, 1992). Considerando nossa primeira hipótese, poderíamos esperar que a cobertura da imprensa fosse impactar negativamente no voto para Dilma?

Uma maneira de tentar responder a essa pergunta é analisando a cobertura da imprensa em 2010. A Figura 1 traz os gráficos que mostram a evolução, quantitativa, da cobertura eleitoral dos jornais Folha de S. Paulo, O Globo e o Estado de S. Paulo, entre janeiro e outubro de $2010 .{ }^{4}$ Percebe-se que à medida em que a campanha ganha intensidade, aumenta-se também a visibilidade dos principais candidatos ao cargo de Presidente da República, medida a partir da média das aparições (citações) do nome de um ou mais dos concorrentes, além de Lula, em uma matéria, editorial, reportagem, coluna, etc., dos veículos mencionados ${ }^{5}$.

4 Embora utilizemos apenas uma análise de importantes jornais impressos, vários estudos já mostraram que eles são bons indicadores da cobertura da imprensa como um todo, inclusive da televisiva, tanto nos EUA quanto no Brasil (PAGE, SHAPIRO e DEMPSEY, 1987; PATTERSON, 1980; AZEVEDO 2000; MUNDIM, 2010). Portanto, neste artigo a cobertura dos jornais impressos será utilizada como um indicador da cobertura dos meios noticiosos em geral.

5 Agradecemos a Alessandra Aldé a disponibilização dos bancos de dados referentes à análise da cobertura da mídia impressa realizada pelo DOXA-IESP nos anos de 2009 e 2011. Agradecemos, também, a Marcus Figueiredo, coordenador do DOXA-IESP, aos bolsistas que participaram da análise de conteúdo e aos financiadores do trabalho. 
Figura 1

Evolução da média de aparições diárias em cada material jornalístico analisado, referentes ao ex-presidente Lula e aos principais candidatos a Presidente da República, nos jornais Folha de S. Paulo, 0 Globo e 0 Estado de S. Paulo, entre janeiro e outubro de 2010

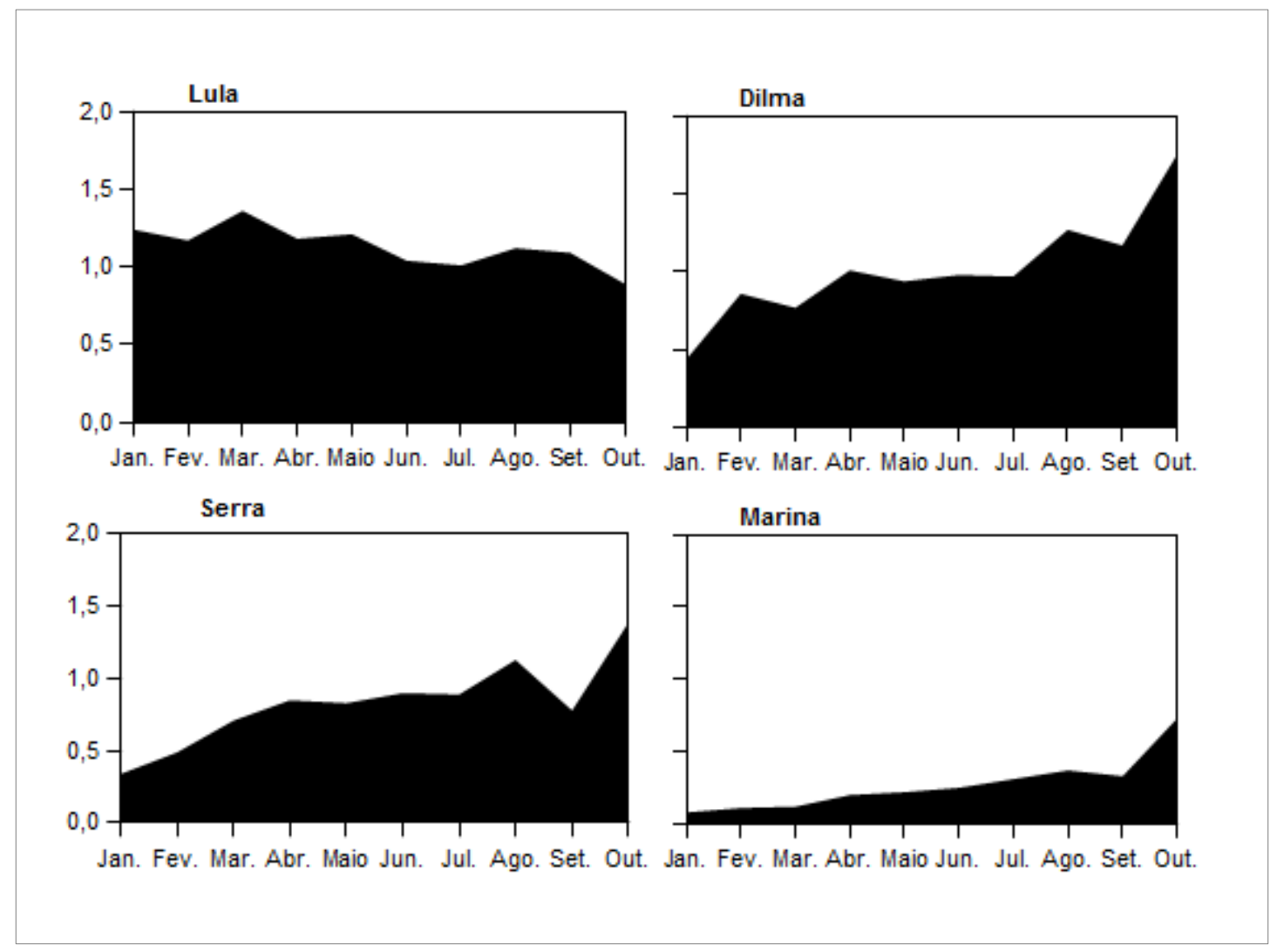

Fonte: DOXA-IESP, 2010

Os gráficos mostram a importância e a presença do ex-presidente Lula durante a disputa. Em grande parte do ano, sua visibilidade nos jornais permaneceu alta, às vezes superior à dos próprios concorrentes ao cargo de Presidente da República. O fato de Lula, após cinco eleições presidenciais, não ser o candidato petista não significou que ele estava ausente da disputa. Na verdade, o ex-presidente esteve presente como sempre, seja do ponto de vista político, já que a decisão era sobre a continuidade do seu estilo de governo, seja do ponto de vista das estratégias de campanha dos candidatos, já que se colocou como o grande puxador de votos da sua candidata. Esse fato não passou despercebido pela 
imprensa.

Mas a análise da cobertura dos jornais não se resume a um mapeamento quantitativo acerca da visibilidade das figuras políticas mais importantes da disputa. O modo como os concorrentes são apresentados importa. O resultado dessa análise, qualitativa, pode ser visto nos gráficos da Figura 2. Eles trazem a evolução do conteúdo positivo, negativo, neutro e equilibrado publicado sobre Lula, Dilma, Serra e Marina nas páginas da Folha, Globo e do Estadão.

\section{Figura 2}

Evolução do percentual positivo, negativo, neutro e equilibrado da cobertura, referentes ao ex-presidente Lula e aos principais candidatos a Presidente da República, nos jornais Folha de S. Paulo, 0 Globo e 0 Estado de S. Paulo, entre janeiro e outubro de 2010.

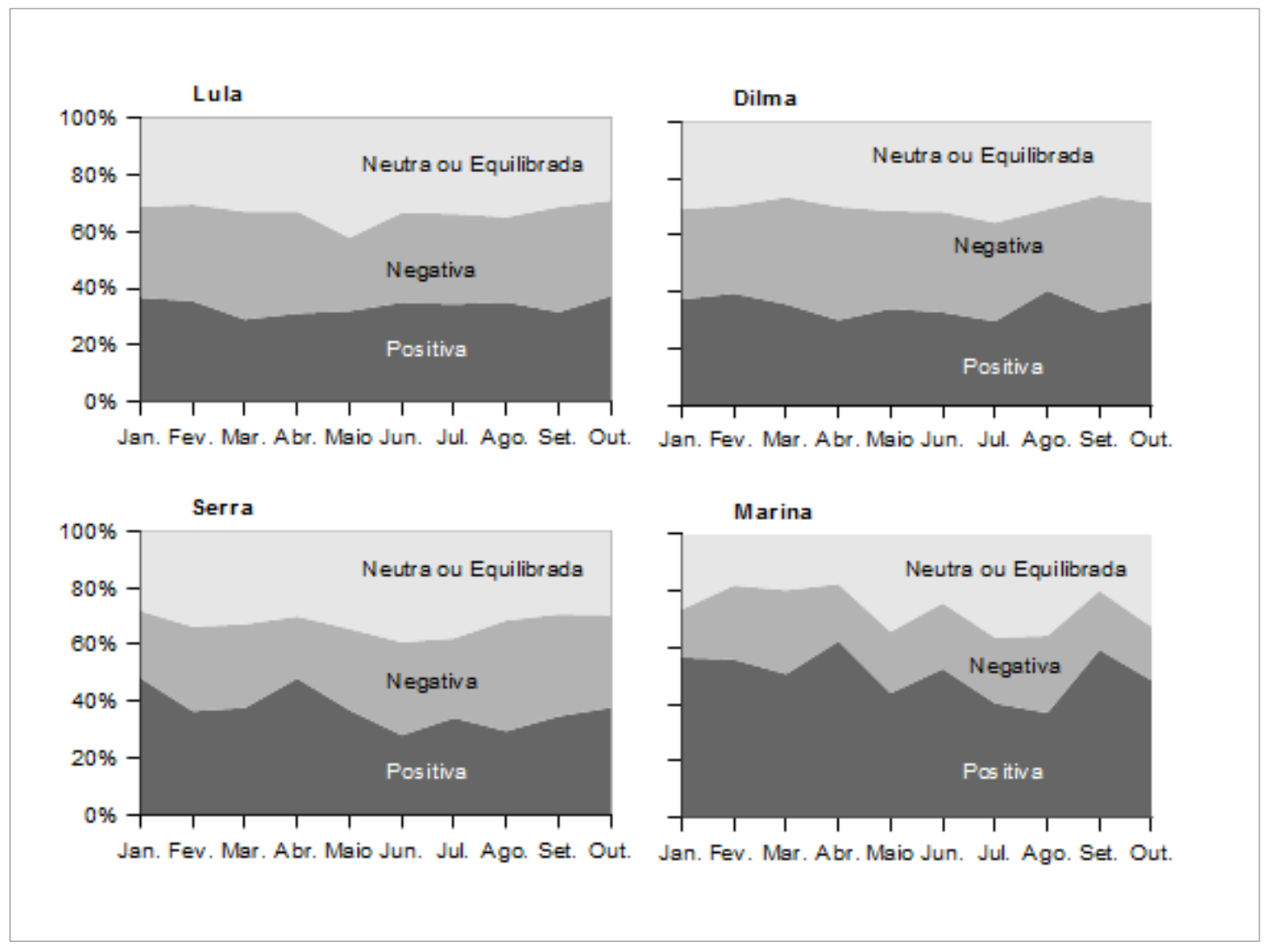

Fonte: DOXA-IESP, 2010 
BEZERRA, H. D.; MUNDIM, P. S. Qual foi o papel das variáveis midiáticas na eleição...

Comparado à eleição de 2006 (ALDÉ, FIGUEIREDO e MENDES, 2007), os gráficos mostram um maior equilíbrio da cobertura realizada pelos três jornais. Se houve uma cobertura que destoou, foi a de Marina Silva (PV), bem mais positiva do que negativa, neutra ou equilibrada. Entre setembro e outubro de 2010, por exemplo, a candidata do PV teve cerca de $60 \%$ de cobertura positiva. Dilma e Serra nunca chegaram a alcançar $40 \%$. Esse pode ter sido uma das razões pelas quais a candidata do PV conseguiu melhorar o seu desempenho nas intenções de voto no último mês de campanha.

Tal efeito pode não ter sido maior pela baixa visibilidade da candidata na imprensa, como mostra o gráfico da Figura 1, o que pode ser explicado pela pouca expressão dos partidos envolvidos na chamada candidatura verde. $O$ fator novidade também pode ter ajudado Marina a ter uma cobertura mais afável da mídia, mas nem sempre é o que ajuda um candidato a fortalecer sua imagem nas edições dos noticiosos.

Uma cobertura da imprensa mais equilibrada poderia sugerir que os efeitos midiáticos, em 2010, seriam mais amenos do que em 2006, ou até mesmo inexistentes. Consideramos a primeira perspectiva plausível, mas a última improvável. Em primeiro lugar, mesmo em eleições cuja cobertura foi mais equilibrada, como em 2020, foi possível identificar efeitos midiáticos relevantes (MUNDIM, 2010). Em segundo lugar, entendemos que o fato que desencadeou a cobertura mais negativa em 2006, o escândalo do Mensalão de 2005, teve um efeito de longo prazo tanto na imprensa quanto em parte dos eleitores. Ainda que os efeitos midiáticos em 2010 sejam menores do que em 2006, eles ainda poderão ser encontrados nesta última eleição, a favor dos candidatos da oposição, e contrários à situação.

Da fato, estamos tomando como premissa o efeito que o elemento "persistência temporal" pode ter na fixação de determinados conteúdos na memória do eleitor. No caso, trata-se da persistência de abordagens negativas envolvendo o Governo Lula, o que, podemos supor, pode ter ajudado Serra a amealhar mais votos do que poderia ter ao competir com uma candidata que não apenas fazia parte do governo mas tinha como patrono um dos políticos brasileiros (presidente da República) mais bem avaliados de todos os tempos.

\section{As variáveis dependentes}

As variáveis dependentes foram construídas a partir das perguntas sobre em quem o eleitor votou nas eleições presidenciais de 2010 , no $1^{\circ}$ e no $2^{\circ}$ turnos, com as seguintes categorias: voto em Dilma (45,4\%), Serra (27\%), Marina $(16,5 \%)$ e Outros/Não voto (brancos, nulos e abstenções, 11,1\%), no $1^{\circ}$ turno, e voto em 
Dilma (53,6\%), Serra (34,2\%) e Não voto (brancos, nulos e abstenções, $12,2 \%)$, no $2^{\circ}$ turno $^{6}$.

\section{As variáveis midiáticas}

O nosso principal objetivo foi analisar papel das variáveis midiáticas na eleição presidencial de 2010. Cinco delas estavam disponíveis o ESEB 2010: (1) quanto dias por semana o eleitor lê notícias nos jornais, (2) quanto dias por semana assiste ao Jornal Nacional da Rede Globo, (3) quanto dias por semana assiste ao programa Brasil Urgente, na época na Rede Bandeirantes, (4) se assistiu aos debatas na TV entre os candidatos a presidente e (5) um índice de atenção política, um indicador do nível de exposição e recepção ao conteúdo político dos meios de informação em um dado período de tempo.

As quatro primeiras variáveis permitem-nos obter o nível de exposição autodeclarada dos eleitores aos jornais impressos e aos programas de televisão mencionados acima. Contudo, estudos mostraram que respostas de exposição autodeclaradas aos meios de comunicação podem não se configurar em indicadores confiáveis de exposição à mídia. As pessoas têm dificuldade para estimar corretamente a freqüência com que se expõem aos jornais e aos noticiários, por exemplo, pois essa estimativa não é cognitivamente simples. Assim, ao responderem a perguntas como "quantos dias por semana o Sr.(Sra.) lê jornal?", elas acabam oferecendo meros "palpites" ou superdimensionam seus níveis de exposição aos meios de comunicação (ZALLER e PRICE, 1993; PRIOR 2009a,b).

Outro problema das variáveis que medem os níveis de exposição autodeclarados aos meios de comunicação tem a ver com a diferença conceitual entre exposição e recepção. Segundo Zaller e Price (1993, p.134), a exposição refere-se "à simples exposição às notícias, que entendemos ser qualquer situação na qual uma pessoa entra em contato com eventos particulares ou notícias através de qualquer tipo de meio de comunicação". Já a recepção "exige atenção, compreensão e a retenção da notícia". Essa distinção é importante porque, segundo os autores, "histórias que não são compreendidas e/ou retidas têm pouco importância", pois não são capazes de afetar os estoques de informações, atitudes, opiniões e comportamento dos eleitores.

Para Zaller e Price (1993, p.137) as variáveis que medem os níveis de exposição autodeclarados aos meios de comunicação "são claramente mais adequados para medir a simples exposição (...) do que a recepção". Mas, como mencionado acima, o que realmente importa é "se a mensagem foi realmente

6 Uma descrição mais detalhada destas e das demais variáveis dos modelos encontram-se no apêndice. 
BEZERRA, H. D.; MUNDIM, P. S. Qual foi o papel das variáveis midiáticas na eleição...

recebida" (ZALLER e PRICE, 1993, p.137), ou seja, se a informação disponibilizada foi compreendida e retida.

Zaller e Price (1993) argumentam, convincentemente, que o melhor indicador para exposição, seguida da recepção, aos meios de comunicação em geral, e dos meios de informação política em particular, é um índice de "atenção política" (políticasl awareness) que pode ser construído a partir de algumas variáveis presentes nos surveys eleitorais. Tal indicador não é, e nem tenta ser, um sinônimo para "sofisticação política" ou um índice de "civismo", principalmente porque, em termos teóricos, ele não tem esse objetivo. Conforme Zaller (1992, p.43) assinalou, o índice de "atenção política (...) é uma medida de uma atenção geral, persistente. Como tal, ele não testa diretamente a informação dos indivíduos sobre ou a atenção deles a uma questão particular". De modo mais específico, a:

“atenção política (...) refere-se à extensão da atenção que um indivíduo dá a assuntos políticos e compreende o que foi que ele encontrou. Apenas prestar atenção não é suficiente, uma vez que as pessoas que, por exemplo, assistem às notícias da televisão enquanto estão deitadas no sofá após o jantar e duas taças de vinho irão tipicamente falhar no aprimoramento de seu conhecimento político. Então, a chave para a atenção política tem a ver com a absorção de comunicações políticas" (Zaller, 1992, p.22 - grifo do autor, tradução livre Mundim, P.S.).

Com base nessas considerações, assumimos que o índice de atenção política é um indicador muito mais adequado do que suas "correlatas", seja da exposição e da recepção do conteúdo sobre assuntos e temas político produzidos especialmente pela cobertura da imprensa, seja para captar quaisquer efeitos midiáticos que tenham ocorrido na eleição de 2010. Para construí-lo, inicialmente seguimos a forma tradicional sugerida por Zaller (1992), utilizando a resposta dos eleitores a quatro perguntas sobre conhecimento factual de temas político eleitorais. Contudo, o índice elaborado com tais perguntas alcançou uma confiabilidade muito baixa ( $\alpha$ de Cronbach $=0,397$ ), o que tornaria a sua utilização pouco apropriada.

A solução alternativa, também indicada por Zaller (1992), foi utilizar um conjunto de questões em que era lido para os eleitores o nome de políticos como Lula, Serra, Marina, Aécio Neves, etc., e em seguida era perguntado a que partidos eles eram filiados. Para cada uma dessas perguntas foi construído uma variável dicotômica, sendo 1 para as respostas corretas e 0 para as respostas incorretas, "não sabe", "não conhece o político" e "não respondeu". Os valores dessas variáveis 
foram somados, constituindo-se em uma nova variável. Dessa vez, o índice de atenção política alcançou uma confiabilidade bastante satisfatória ( $\alpha$ de Cronbach $=$ 0,840).

Das demais variáveis midiáticas incluídas no modelo, algo deve ser dito sobre a que se refere ao Brasil Urgente. Embora o foco deste último sejam as notícias locais, de violência e de utilidade pública, e não as políticas, em 2010 Dilma e Serra foram entrevistados pelo apresentador do programa, o jornalista José Luiz Datena.

Tal fato reflete uma transformação importante. Nos últimos anos, programas mais focados no entretenimento e em fait divers passaram, também, a cobrir política e políticas públicas, ainda que de um modo diferente de seus correlatos mais tradicionais (HALLIN 2000; BAUM 2003) ${ }^{7}$. Essa mudança fez com que os políticos, "perseguidores de multidões" por excelência, passassem a adaptar suas estratégias de campanha a essa nova maneira de se comunicar com os eleitores e a ver a participação nesses programas como uma forma de maximizar votos, especialmente entre uma grande parcela de eleitores que não se interessa por política - que é justamente o perfil da audiência desses programas (POPKIN 2006).

\section{As variáveis de controle}

As variáveis de controle foram separadas em dois grupos. O primeiro deles é composto por um conjunto de variáveis demográficas: escolaridade, renda familiar mensal, sexo, região do país e grupo de idade. Como já demonstrado em outro trabalho (MUNDIM, 2010), a escolaridade pode servir como um indicador do nível de atenção política dos eleitores, por isso, ela talvez seja a melhor variável para controlar os seus efeitos. Em todo caso, pode-se assumir que ela também irá funcionar como uma boa variável de controle para os demais preditores midiáticos.

Como mencionado anteriormente, acreditamos que alguns fatores que influenciaram o voto dos eleitores em 2006 também o fizeram em 2010. Nesse sentido, a região do país é uma variável de grande interesse para a nossa análise, já que estudos sobre a eleição de 2006 mostraram que "comparado a 2002, o percentual de votos válidos nas regiões centro-sul do país, onde alcançava bons resultados, diminuiu; e aumentou nas regiões norte e nordeste, onde o Programa Bolsa Família (BF) distribuiu mais recursos" (SOARES e TERRON, 2008, p.270). Com base em análises como essa, foram criadas duas variáveis binárias, Centro-

7 Por exemplo, "quando cobrem uma guerra (...) [as soft news e os programas de jornalismo e entretenimento] focam mais nos dramas humanos [e nos valores morais] do que na geopolítica, nas relações internacionais ou na diplomacia (...) [elas] enfatizam os custos pessoais" (Popkin, 2006, p.333 tradução livre Mundim, P.S.). 
BEZERRA, H. D.; MUNDIM, P. S. Qual foi o papel das variáveis midiáticas na eleição...

Oeste/Sul e Nordeste/Norte, que buscam estimar os efeitos regionais do voto em 2010.

No segundo grupo de variáveis de controle encontram-se aqueles que chamamos de político-econômicas: a preferência partidária pelo PT, PSDB e PV, a avaliação do governo Lula, se recebe o Bolsa Família e as avaliações econômicas retrospectivas sociotrópica e pessoal dos últimos doze meses. Elas foram incluídas com o intuito de colocar a nossa análise em consonância com estudos clássicos sobre as razões do voto (LAZARSFELD, BERELSON e GAUDET, 1948 [1944]; CAMPBELL et al, 1967; DOWNS, 1999 [1957]; KEY, 1966; FIORINA, 1981). Também acreditamos que seus efeitos, em 2010, foram bastante semelhantes aos observados em 2006.

\section{Análise dos resultados}

Com base nas variáveis descritas acima, foram estimados dois modelos logísticos multinomiais, tendo como variável dependente o voto dos eleitores no $1^{\circ} \mathrm{e}$ no $2^{\circ}$ turno da eleição de 2010, e o voto em Dilma como categoria de referência. Os resultados presentes na tabela 1 sugerem que quatro das cinco variáveis midiáticas incluídas no modelo exerceram uma influência estatisticamente significativa no comportamento dos eleitores brasileiros na eleição presidencial de 2010, mesmo que tenham sido mais presentes no $2^{\circ}$ turno. Esses resultados reforçam o nosso argumento a favor de uma participação mais ativa da mídia na decisão do voto dos eleitores, mesmo que não tenha sido necessariamente decisivo para o resultado final do pleito.

Tabela 1

Resultado das regressões logísticas multinomiais - Eleição presidencial de $2010^{a}$

\begin{tabular}{|l|c|c|c|c|c|}
\hline & \multicolumn{3}{|c|}{$1^{\circ}$ Turno } & \multicolumn{2}{c|}{$2^{\circ}$ Turno } \\
\hline & Serra & Marina & $\begin{array}{c}\text { Outros/ } \\
\text { Não Voto }\end{array}$ & Serra & Não voto \\
\hline Intercepto & 4,236 & 1,183 & 0,960 & 3,632 & 0,672 \\
\hline & $(0,559)^{* * *}$ & $(0,602)^{*}$ & $(0,683)$ & $(0,512)^{* * *}$ & $(0,645)$ \\
\hline Atenção Política (padronizada) & 0,124 & 0,027 & $-0,099$ & 0,167 & $-0,005$ \\
\hline & $(0,079)$ & $(0,086)$ & $(0,101)$ & $(0,072)^{* *}$ & $(0,093)$ \\
\hline Jornal & 0,021 & 0,073 & 0,009 & 0,006 & 0,132 \\
\hline Jornal Nacional & $(0,053)$ & $(0,057)$ & $(0,065)$ & $(0,048)$ & $(0,060)^{* *}$ \\
\hline & 0,003 & $-0,001$ & $-0,050$ & 0,009 & $-0,052$ \\
\hline Datena (Brasil Urgente) & $(0,029)$ & $(0,032)$ & $(0,035)$ & $(0,026)$ & $(0,033)$ \\
\hline
\end{tabular}


OPINIÃO PÚBLICA, Campinas, vol. 17, n², Novembro, 2011 , p. 452-476

\begin{tabular}{|c|c|c|c|c|c|}
\hline & $(0,030)$ & $(0,033)$ & $(0,036)$ & $(0,027)$ & $(0,033)^{*}$ \\
\hline \multirow[t]{2}{*}{ Debates } & 0,196 & $-0,042$ & $.0,133$ & 0,035 & $-0,290$ \\
\hline & $(0,115)^{*}$ & $(0,129)$ & $(0,144)$ & $(0,105)$ & $(0,136)^{* * *}$ \\
\hline \multirow[t]{2}{*}{ Avaliação do presidente Lula } & $\cdot 1,214$ & $-1,002$ & $-0,692$ & $-1,191$ & $-0,634$ \\
\hline & $(0,128)^{* * * *}$ & $(0,139)^{* * * *}$ & $(0,156)^{* * * *}$ & $(0,120)^{* * * *}$ & $(0,149)^{* * * *}$ \\
\hline \multirow[t]{2}{*}{ PT: partido preferido } & $\cdot 2,185$ & $-1,117$ & $.0,924$ & $-1,987$ & $-0,929$ \\
\hline & $(0,212)^{* * * *}$ & $(0,183)^{* * * *}$ & $(0,197)^{* * * *}$ & $(0,187)^{* * * *}$ & $(0,194)^{* * * *}$ \\
\hline \multirow[t]{2}{*}{ PSDB Partido preferido } & 1,995 & 0,562 & 0,649 & 2,381 & 1,333 \\
\hline & $(0,300)^{* * * *}$ & $(0,379)$ & $(0,427)$ & $(0,322)^{* * * *}$ & $(0,412)^{* * * *}$ \\
\hline \multirow[t]{2}{*}{ PV: partido preferido } & $.0,159$ & 2,044 & 0,824 & 0,052 & 0,474 \\
\hline & $(0,513)$ & $(0,384)^{* * * *}$ & $(0,514)$ & $(0,306)$ & $(0,367)$ \\
\hline \multirow[t]{2}{*}{ Avaliação econômica do país } & $-0,257$ & 0,039 & 0,085 & $-0,267$ & $.0,123$ \\
\hline & $(0,120)^{* *}$ & $(0,138)$ & $(0,155)$ & $(0,110)^{* *}$ & $(0,143)$ \\
\hline \multirow[t]{2}{*}{ Avaliação econômica pessoal } & $.0,212$ & $.0,003$ & $.0,070$ & 0,176 & $.0,025$ \\
\hline & $(0,108)^{* *}$ & $(0,122)$ & $(0,135)$ & $(0,098)^{*}$ & $(0,128)$ \\
\hline \multirow[t]{2}{*}{ Recebe bolsa família } & $.0,042$ & $-0,288$ & $-0,474$ & $-0,056$ & $-0,031$ \\
\hline & $(0,192)$ & $(0,237)$ & $(0,258)^{*}$ & $(0,180)$ & $(0,239)$ \\
\hline \multirow[t]{2}{*}{ Sexo (Homem) } & $-0,204$ & $-0,326$ & $-0,064$ & $-0,139$ & 0,110 \\
\hline & $(0,140)$ & $(0,156)^{*}$ & $(0,172)$ & $(0,127)$ & $(0,164)$ \\
\hline \multirow[t]{2}{*}{ Idade } & $.0,044$ & $-0,052$ & 0,022 & $-0,013$ & $-0,006$ \\
\hline & $(0,059)$ & $(0,065)$ & $(0,073)$ & $(0,053)$ & $(0,069)$ \\
\hline \multirow[t]{2}{*}{ Escola } & 0,041 & 0,440 & 0,194 & 0,096 & 0,097 \\
\hline & $(0,084)$ & $(0,093)^{* * * *}$ & $(0,104)^{*}$ & $(0,076)$ & $(0,098)$ \\
\hline \multirow[t]{2}{*}{ Renda Familiar Mensal } & $\cdot 0,184$ & 0,226 & $\cdot 0,005$ & $-0,117$ & $-0,057$ \\
\hline & $(0,097)^{*}$ & $(0,101)^{* * *}$ & $(0,119)$ & $(0,086)$ & $(0,111)$ \\
\hline \multirow[t]{2}{*}{ CO/SUL } & 0,481 & $.0,482$ & $.0,500$ & 0,510 & $-0,263$ \\
\hline & $(0,169)^{* * *}$ & $(0,208)^{* * *}$ & $(0,238)^{* * *}$ & $(0,157)^{* * * *}$ & $(0,211)$ \\
\hline \multirow[t]{2}{*}{$\mathrm{NO} / \mathrm{NE}$} & $.0,046$ & 0,159 & 0,124 & 0,028 & $-0,549$ \\
\hline & $(0,167)$ & $(0,177)$ & $(0,196)$ & $(0,150)$ & $(0,196)^{* * *}$ \\
\hline$\chi^{2}$ & \multicolumn{2}{|l|}{$774,318^{* * * *}$} & & \multicolumn{2}{|l|}{$639,418^{* * *}$} \\
\hline -2 Log Likelihood & 3754,028 & & & 2809,267 & \\
\hline Pseudo $\mathrm{R}^{2}$ (McFadden) & 0,171 & & & 0,185 & \\
\hline $\mathrm{N}$ & 1817 & & & 1814 & \\
\hline
\end{tabular}

a Dilma é a categoria de referência. Erros-padrão robustos entre parênteses.

*** $\mathrm{p}<0.01,{ }^{* *} \mathrm{p}<0.05, * \mathrm{p}<0.1$

Fonte: ESEB 2010

A análise apresentada anteriormente mostrou que, em 2010, os principais jornais do país fizeram uma cobertura dos candidatos mais neutra e equilibrada do que negativa ou positiva. Em cenários como esse, seria possível não encontramos efeito midiático algum, uma vez que os fluxos informacionais disponíveis refletiriam esse equilíbrio. Contudo, os dados da Tabela 1 mostram algo diferente. No $2^{\circ}$ turno da última eleição, o aumento de um desvio-padrão na variável que mede a atenção política aumentavam em $18,2 \%$ as chances de se votar em Serra, e não em Dilma, 
BEZERRA, H. D.; MUNDIM, P. S. Qual foi o papel das variáveis midiáticas na eleição...

mantidas constantes as demais variáveis do modelo8.

Esse resultado está dentro daquilo que esperávamos encontrar. Análises anteriores sobre a eleição de 2006 mostraram que a cobertura político-eleitoral dos principais meios de informação do país foi capaz de afetar a decisão do voto dos eleitores a favor dos candidatos de oposição, contribuindo para a ocorrência do $2^{\circ}$ turno e para o processo de mudança da base social do voto em Lula (MUNDIM, 2010, 2011). O fato de o resultado final da eleição ter sido favorável ao expresidente não elimina o fato, politicamente relevante, de a cobertura da imprensa ter ajudado a delinear os contornos que as preferências dos eleitores apresentaram em 2006.

Para reforçarmos essa interpretação, estimamos outros dois modelos multinomiais com as mesmas variáveis explicativas, mas tendo o voto no $1^{\circ}$ e no $2^{\circ}$ turnos da eleição de 2006 como variáveis dependentes, e o voto em Lula como categoria de referência. Os resultados foram ainda mais substantivos. O aumento de um desvio-padrão da variável que mede a atenção política aumentava em $61,9 \%$ ( $\beta$ $=0.482, p<.000$ ) as chances de o eleitor dizer que havia votado em Alckmin, e não em Lula, no $1^{\circ}$ turno da eleição de 2006, mantidas constantes as demais variáveis do modelo. No $2^{\circ}$ turno, o aumento de um desvio-padrão na variável que mede a atenção política aumentava em $62,3 \%(\beta=0.484, \mathrm{p}<.000)$ as chances de o eleitor dizer que havia votado em Alckmin, e não em Lula, ceteris paribus ${ }^{9}$.

A provável razão desses efeitos foi a intensa e negativa cobertura da imprensa, de 2005 a 2006, sobre os escândalos de corrupção envolvendo o governo Lula. Embora um tom mais ameno tenha predominado em 2010, os resultados da Tabela 1 mostram que isso não foi suficiente para eliminar a predisposição dos eleitores mais expostos ao conteúdo dos principais veículos de informação do país a votarem em Serra na última eleição. Nesse sentido, se alguns dos fatores que levaram Lula a se reeleger continuaram a afetar o comportamento dos eleitores a favor de Dilma em 2010, o mesmo ocorreu com alguns dos fatores que Ihe foram desfavoráveis em 2006, ainda que, em relação a cobertura da imprensa, os efeitos tenham se tornado mais amenos.

Duas considerações podem ser feitas em relação às variáveis que medem os

8 Como a discussão sobre a construção do índice de atenção política mostrou, existem várias maneiras de construí-lo. Essa variação acontece não apenas dentro de cada survey, mas também entre pesquisas feitas com diferentes propósitos e períodos de tempo. Isso significa, por exemplo, que em um survey poderemos construir um que varia de 0 a 7, enquanto em outro poderemos construir um índice que varia de 0 a 17. Para facilitar a comparação dos efeitos da atenção política em diferentes pesquisas, Zaller (1992) sempre utiliza a forma padronizada desta variável $(\mu=0 ; \sigma=1)$. Essa transformação não interfere na significância estatística da variável em questão, ou das demais variáveis incluídas no modelo.

9 Por razões de espaço, não disponibilizamos os resultados da estimação desses modelos neste artigo. Mas eles podem ser obtidos diretamente com os autores. 
níveis de exposição auto-declaradas aos jornais impressos e aos programas televisivos, entre eles o Jornal Nacional. Por um lado, e pelas limitações expostas anteriormente, não surpreende que elas tenham deixado de alcançar significância estatística em relação ao voto dos principais candidatos - mesmo que, de maneira sugestiva, os sinais de seus coeficientes dêem suporte à interpretação apresentada sobre os efeitos do índice de atenção política, ao mostrarem um cenário desfavorável a Dilma em relação a Serra. Por outro lado, os resultados da Tabela 1 também sugerem que uma maior exposição aos jornais e ao programa Brasil Urgente aumentava a probabilidade de o eleitor não comparecer às urnas ou de votar branco ou nulo, mas não em Dilma.

A imprensa escrita geralmente realiza uma ampla cobertura das eleições, o que pode influenciar positivamente a participação política. Estudos clássicos sobre comportamento eleitoral haviam mostrado uma associação positiva entre exposição a jornais e interesse por política (LAZARSFELD, BERELSON e GAUDET, 1948 [1944]). Por essa razão, o resultado apresentado na Tabela 1 acaba sendo, em certa medida, contra intuitivo.

Ao mesmo tempo, eles podem ser a indicação de um efeito midiático identificado por Patterson (1994). No longo prazo, os anos de cobertura negativa em relação ao governo Lula, especialmente após o escândalo do Mensalão, em 2005, não tiveram como conseqüência apenas a rejeição de uma parcela dos eleitores aos candidatos do PT. Ao solaparem, ao menos em tese, o último baluarte da ética política entre os grandes partidos brasileiros, o "viés antipolítico" da imprensa poder ter contribuído para a apatia política e a desconfiança do público em relação aos políticos, por parte de alguns, no $2^{\circ}$ turno da eleição principalmente em uma disputa que não acabou sendo tão acirrada.

O mesmo efeito midiático pode ter ocorrido com o público do Brasil Urgente. A linguagem mais assertiva, opinativa e crítica do apresentador do programa, muitas vezes dirigidas a políticos envolvidos em escândalos de corrupção e a autoridades públicas ditas incompetentes, provavelmente acabaram incentivando os telespectadores do programa a terem uma atitude mais cínica e desinteressada, influenciado-os a votarem branco e nulo, ou a absterem-se. Esse efeito negativo na participação política dos eleitores parece não ter sido diluído com a cobertura mais intensa que o programa fez das eleições de 2010, inclusive com entrevistas ao vivo com os principais candidatos. Patterson (2000), mais uma vez, parece estar certo, mas agora em relação à cobertura política das chamadas soft news.

Por fim, o fato de o eleitor ter assistido a alguns, ou a todos os debates, fazia aumentar as chances de ele votar em Serra, e não em Dilma, ao menos no $1^{\circ}$ 
turno, mantidas constantes as demais variáveis do modelo ${ }^{10}$. A falta de experiência e de carisma da candidata do PT em debates pode ter contribuído para esse resultado. É interessante notar, ainda, que uma maior exposição aos debates presidenciais também está associado a uma menor probabilidade de o eleitor deixar de comparecer às urnas e de votar branco ou nulo. Mesmo que muitas vezes herméticos, truncados e tediosos, os debates parecem diminuir as chances de apatia política, ao menos em 2010.

Os resultados apresentados mostram que, das variáveis políticas e econômicas, as preferências partidárias e as avaliações de governo e da econômica do país mostraram-se fortes preditores de voto em todos os modelos estimados, e sempre na direção correta.

Eleitores com preferência pelo PT, PSDB e PV tinham maior probabilidade de votar em seus respectivos candidatos. Já os eleitores mais satisfeitos com o governo e/ou com a economia, do país ou a pessoal, tinham maiores chances de votar pela continuidade. Como já mostraram vários estudos (KEY 1966; FIORINA 1981; CARREIRÃO 2002), governos bem avaliados têm maiores chances de permanecerem no poder, reelegendo-se ou fazendo um sucessor. Esse resultado torna-se ainda mais provável em um cenário como o da eleição de 2010 , quando, de acordo com os dados do ESEB, 93,3\% dos eleitores brasileiros avaliavam o governo Lula como bom ou ótimo ${ }^{11}$.

Dilma também se beneficiou da avaliações econômicas dos eleitores. Quanto mais eles viam, de maneira positiva, as situações econômicas do país e a pessoal nos últimos 12 meses, maiores eram as probabilidades de preferirem o voto pela continuidade, e não em Serra, da oposição.

Mais uma vez, os números eram favoráveis à campanha petista. Embora a situação fosse menos dramática do que em 2008 - principalmente - e 2009, o mundo estava longe de ter deixado a crise econômica mundial para trás. Ainda assim, 55,1\% dos eleitores consideravam a situação econômica do país melhor em outubro de 2010 do que nos últimos 12 meses, assim como 50,7\% consideravam a sua situação econômica pessoal melhor. Essas avaliações são ainda mais importantes para a decisão do voto quando se sabe que o eleitor pode comparar o

10 Intuitivamente, acreditamos que a variável debates teve um melhor desempenho entre todas as de exposição autodeclarada devido à menor dificuldade cognitiva para responder as suas opções de resposta (ver anexo). Mas uma resposta definitiva para essa colocação dependeria de um teste mais consistente.

11 De fato, esse número pode parecer um pouco exagerado. Outras pesquisas realizadas à véspera da eleição, como por exemplo, a do Datafolha do dia 26 de Outubro de 2010 ( $N=4066$, margem de erro de \pm 2, com $95 \%$ de nível de confiança), mostraram que $83 \%$ dos eleitores brasileiros avaliaram o governo Lula como bom ou ótimo, e $13 \%$ como regular. Acreditamos que o resultado do ESEB pode ter sido "inflado" porque o questionário não apresentou a opção de "regular" ao respondente. 
desempenho dos governos do PSDB durante as crises econômicas dos anos 1990 e início de 2000, com a maneira como o governo petista lidou com a crise econômica do final da primeira década do século 21.

O formato das variáveis "econômicas", ambas na mesma escala de grandeza, também nos permitem comparar qual tipo de voto econômico foi mais importante em 2010: o pessoal ou o sociotrópico. Estudos anteriores, nos EUA e no Brasil (KIEWIET 1983; CAMARGOS 1999), já haviam mostrado que os eleitores tendem a dar mais importância, na hora de votar, à situação econômica nacional do que à sua condição econômica pessoal. Em 2010, essa também foi a realidade encontrada, especialmente no $2^{\circ}$ turno, quando a razão entre os coeficientes do voto econômico sociotrópico e pessoal era de 1,52.

Como Lula em 2006, Dilma pode se beneficiar das avaliações positivas do mandato que terminava e dos $27,7 \%$ de eleitores que disseram ser o PT o partido de que mais gostavam. É inegável, portanto, a força desses fatores como mecanismos de transferência de votos. Mas é inegável, também, que em 2010 eles, mais uma vez, funcionaram como mecanismos de resistência - ou como "escudos", para usar o termo cunhado por Rennó (2007) - para uma parcela dos eleitores contra os efeitos de longo prazo da cobertura negativa da imprensa.

Em relação às demais variáveis de controle, os dados da Tabela 1 mostram que um eleitor beneficiário do Bolsa Família tinha $37,8 \%$ de chances a mais de votar em Dilma, ao invés de abster-se, votar em branco ou nulo, mantidas constantes as demais variáveis do modelo. Embora esse efeito seja salutar do ponto de vista da participação política, especialmente entre as pessoas de baixa renda os beneficiários do programa - esperava-se que a variável alcançasse significância estatística na definição do voto em relação aos candidatos.

Ao menos em uma análise com dados individuais, as variáveis econômicas e de avaliação de governo parecem ter sido fatores mais importante do que participar do Bolsa Família. O programa de transferência de renda também pode não ter sido o único critério utilizado pelos eleitores mais pobres para preferirem a continuidade do governo Lula (BOHN, 2011). Além disso, é provável que o programa tenha tido efeitos agregados, na vida das comunidades e cidades com grande concentração de beneficiários, mais difíceis de mensurar com dados individuais, mas já detectada por análises agregadas sobre a eleição de 2006 (ZUCCO, 2008; HUNTER e POWER, 2007; ABENSUR, CRIBARI-NETO E MENEZES, 2007; CÂNEDO-PINHEIRO, 2009; MARQUES et al, 2009).

Entre as variáveis sociodemográficas, o sexo do eleitor foi mais importante na decisão do voto entre Dilma e Marina do que entre Dilma e Serra. Os homens preferiam votar na petista, e não na candidata do PV. No $2^{\circ}$ turno, não houve diferença, o que mostra que as questões de gênero podem ter ficado em segundo 
BEZERRA, H. D.; MUNDIM, P. S. Qual foi o papel das variáveis midiáticas na eleição...

plano na eleição de 2010, pelo menos no que se refere às variáveis mais importantes para a decisão do voto do eleitor.

Outro dado relevante tem a ver com as variáveis renda familiar mensal e escolaridade, cujo aumento faziam crescer as chances de se votar em Marina, e não em Dilma. Esse cenário pode refletir a recorrência de um fato observado em 2006, quando eleitores de maior renda e da escolaridade votaram contra Lula - em 2002 isso não aconteceu, e a influência das novas mídias, uma possibilidade apresentada por autores como Costa (2011). Afinal, são justamente os eleitores de maior renda e escolaridade os que mais têm acesso e, conseqüentemente, mais utilizam a Internet em busca de informações e para uso de redes sociais (RESENDE e CHAGAS, 2011). Mas, até agora, nenhum estudo apresentou evidências realmente convincentes de que as novas mídias foram as responsáveis pelo relativo sucesso de Marina, candidata do PV.

\section{Considerações finais}

Qual foi o papel das varáveis midiáticas na eleição de 2010? Os modelos estimados com os dados do ESEB mostraram que, em grande medida, elas foram mais favoráveis à Serra do que a Dilma. Por exemplo, eleitores com maior atenção política - que capta justamente a exposição e a recepção dos eleitores aos fluxos de informação política disponibilizadas, especialmente, pela cobertura da imprensa tinham maior probabilidade de votar no tucano do que na petista. O desempenho do candidato do PSDB nos debates também o ajudou a ser mais competitivo do que a princípio se poderia imaginar.

Mas, independente do que o resultado da eleição de 2010 possa sugerir, as análises feitas neste artigo nos permitem dizer, com certa segurança, que os meios de comunicação - incluindo a imprensa - continuam a desempenhar um papel importante durante as eleições. O que não podemos é assumir posicionamentos extremos, seja para defender que a mídia, por alguma razão, perdeu seu poder de influenciar as atitudes e a opinião dos eleitores, como muitos analistas e pesquisadores sugeriram em 2006, seja para defender posições que ainda acreditam em meios de comunicação "todo poderosos".

Essa visão, mais ponderada, talvez seja uma das razões pelas quais Dilma elegeu-se com um percentual de votos válidos $(56,1 \%)$ menor do que Lula em 2002 $(61,3 \%)$ e 2006 (60,8\%), mesmo com um governo petista com cerca de $85 \%$ de aprovação. Acreditamos que, por trás desses números, exista um efeito midiático de longo prazo que se iniciou em 2005, cuja persistência temporal se fez sentir em 2010. Mas, conforme pressupõe o principal marco teórico utilizado neste artigo (ZALLER, 1992), o poder de influência das variáveis midiáticas sobre o voto sempre 
ocorre em interação com outros fatores políticos, econômicos e sociais que envolvem a vida das pessoas, e que podem tanto intensificar quanto limitar quaisquer efeitos midiáticos. Isso, no entanto, está longe de significar que as variáveis midiáticas tenham perdido importância política ou que não ajudem a explicar os diferentes comportamentos dos eleitores.

Esperamos, com este artigo, ter contribuído para um melhor entendimento sobre como diferentes variáveis midiáticas interferem no processo de decisão do voto dos eleitores brasileiros. Esperamos, também, ter mostrado que olhar apenas para o resultado final das urnas não é a estratégia de análise mais adequada para entendermos o papel desempenhado pelos meios de comunicação em uma eleição.

\section{Referências Bibliográficas}

ABENSUR, T. C.; CRIBARI-NETO, F.; MENEZES, T. A. Impactos do Programa Bolsa Família nos resultados das eleições presidenciais no Brasil em 2006. In: XXXV Encontro Nacional de Economia (ANPEC), Recife (PE), 2007.

ALDÉ, A.; FIGUEIREDO, M. F.; MENDES, G. Imprensa e eleições presidenciais: natureza e consequências da cobertura das eleições de 2002 e 2006. In: LIMA, V. (org.). A Mídia nas Eleições de 2006. São Paulo: Editora Fundação Perseu Abramo, 2007.

AMARAL, R. "As Eleições de 2006 e a Emergência das grandes massas no processo político". Comunicação e Política, vol. 24, n 3, p. 7-17, 2006.

AZEVEDO, F. A. Imprensa, Campanha presidencial e agenda da mídia. In: RUBIM, A. (org.). Mídia e Eleições de 1998: João Pessoa/Salvador: Editora Universitária/UFPB, FACOM/UFBA, 2000.

BAUM, M. Soft News Goes to War. Princeton: Princeton University Press, 2003.

BEZERRA, H. Mídia e política. Goiânia: Editora da UFG, 2007.

BOHN, S. "Social Policy and vote in Brazil: Bohna Familia and the shifts in Lula's electoral base". Latin American Research Review, vol. 46, n 1, p. 54-79, 2011.

CAMARGOS, M. B. Do bolso às urnas: a influência da economia na escolha entre Fernando Henrique e Lula nas eleições de 1998. Rio de Janeiro. Dissertação de Mestrado em Ciência Política, IUPERJ, 1999. 
CANÊDO-PINHEIRO, M. Bolsa Família ou desempenho da economia? Determinantes da reeleição de Lula em 2006: In: XXXVII Encontro Nacional da ANPEC, Foz do Iguaçu (PR), 2009.

CARRARO, A. et al. "É a economia, companheiro: uma análise empírica da reeleição de Lula com base em dados municipais". IBMEC MG Working Paper, Belo Horizonte, 2007.

CARREIRÃO, Y. A Decisão do voto nas eleições presidenciais brasileiras. Rio de Janeiro/Florianópolis: Editora FGV/ Editora da UFSC, 2002.

COIMBRA, M. A mídia teve algum papel durante o processo eleitoral de 2006. In: LIMA, V. (org.). A Mídia nas Eleições de 2006. São Paulo: Editora Fundação Perseu Abramo, 2007.

CONVERSE, P. E."Information flow and the stability of partisan attitudes", Public Opinion Quarterly, vol.26, p. 578.599, 1962.

COSTA, C. T. "O papel da internet na conquista dos votos de Marina Silva". Interesse Nacional, $\mathrm{n}^{\circ} 13$, p. 59.75, 2011.

CURRAN, J. Media and Democracy. In: ANDERSEN, M. B. (org.) Media and Democracy. Oslo: University of Oslo Press, 1996.

DOWNS, A. Uma Teoria Econômica de Democracia. São Paulo: EDUSP, 1999 [1957].

FIORINA, M. P. Retrospective Voting in American Nacional Elections. New Haven: Yale University Press, 1981.

HALLIN, D. La Nota Roja: Popular Journalism and the Transition to Democracy in Mexico. In: SPARK, C.; TULLOCH, J. (orgs.). Tabloid Tales: Global Debates Over Media Standards. New York: Roman and Littlefield Publishers, 2000.

HUNTER, W.; POWER, T. "Rewarding Lula: Executive Power, Social Policy, and the Brazilian Elections of 2006". Latin American Politics and Society, vol. 49, n 1, p. 1-30, 2007.

KAMEL, A. Rede Globo: os fatos. In: LIMA, V. (org.). A Mídia nas Eleições de 2006. São Paulo: Editora Fundação Perseu Abramo, 2007.

KEY, V. O. The Responsible Electorate. Cambridge: Harvard University Press, 1966.

KIEWIET, D. R. Macroeconomics and Micropolitics. Chicago: The University of Chicago Press, 1983.

KUCINSKI, B. O antilulismo na campanha de 2006 e suas raízes. In: LIMA, V. (org.). A Mídia nas Eleições de 2006. São Paulo: Editora Fundação Perseu Abramo, 2007.

LATTMAN-WELTMAN, F. et al. A imprensa faz e desfaz um presidente. Rio de Janeiro: Editora Nova Fronteira, 1994.

LAZARSFELD, P. F.; BERELSON, B. \& GAUDET, H. The People's Choice. New York: Columbia University Press, 1948 [1944]. 
MAIER, J. "The impact of political scandals on political support: an experimental test of two theories". International Political Science Review, vol. 32, n³ 3, p. 283-302, 2011

MARQUES, R. M. et al. "Discutindo o papel do Programa Bolsa família na decisão das eleições presidenciais brasileiras de 2006", Revista de Economia Política, vol. 29, n 1, p. 14 132, 2009.

MAIN, B. "As metamorfoses do governo representativo". Revista Brasileira de Ciências Sociais, $n^{\circ} 29,1995$

MUNDIM, P. S. "Imprensa e voto nas eleições presidenciais Brasileira”. 162 p. Rio de Janeiro. Tese de Doutorado em Ciência Política, IUPERJ, 2010.

A cobertura da imprensa e o realinhamento eleitoral de 2006. Anais do IV Congresso Latino-americano da WAPOR, Belo Horizonte (MG), 2011.

NASSIF, L. A longa noite de São Bartolomeu. In: LIMA, V. (org.). A Mídia nas Eleições de 2006. São Paulo: Editora Fundação Perseu Abramo, 2007.

NICOLAU, J.; PEIXOTO, V. Uma disputa em três tempos: uma análise das bases municipais das Eleições Presidenciais de 2006. XXXI Encontro Anual da ANPOCS, Caxambu, 2007.

PAGE, B.; SHAPIRO, R.; DEMPSEY, G. "What moves public opinion". American Political Science Review, vol. 81, n 1, p. 24.43, 1987.

PATTERSON, T. E. The Mass media election. New York: Preager Publishers, 1980.

Out of Order. New York: Vintage Books, 1994.

Doing well and doing good: how soft news and critical journalism are shrinking the news audience and weakening democracy - And what news outlets Can Do About It, John F. Kennedy School of Government Faculty Research Working Papers Series, p. 1-28, 2000.

POPKIN, S. L. The reasoning voter. Chicago: The Chicago University Press, 1994.

"Changing media, changing politics". Perspectives on politics, vol. 4, p. 327-341, 2006.

PRIOR, M. "Improving media effects research through better measurement of news exposure". The Journal of Politics, vol. 71, n 3, p. 893-908, 2009a.

The immensebly inflated news audience: assessing bias in self-reported news exposure, Public Opinion Quarterly, vol. 73, n 1, p. 130-143, 2009b.

RENNÓ, L. "Escândalos e Voto: as eleições presidenciais brasileiras de 2006". Opinião Pública, Campinas, vol. 13, $\mathrm{n}^{\circ}$ 2, p. 260-282, 2007.

RESENDE, J. F.; CHAGAS, J. S. C. Eleições no Brasil em 2010: comparando indicadores político-eleitorais em surveys e na internet. Anais do IV Congresso Latino-americano da WAPOR, Belo Horizonte, 2011. 
BEZERRA, H. D.; MUNDIM, P. S. Qual foi o papel das variáveis midiáticas na eleição...

RUBIM, A. Ética da política e ética na política nas eleições de 2006. In: LIMA, V. (org.). A Mídia nas Eleições de 2006. São Paulo: Editora Fundação Perseu Abramo, 2007.

SCHUDSON, M. The power of news. Cambridge: Harvard University Press, 1995.

SILVEIRA, S A. Combates na fronteira eletrônica: A internet nas eleições de 2006. In: LIMA, V. (org.). A Mídia nas eleições de 2006. São Paulo: Editora Fundação Perseu Abramo, 2007.

VIANNA, R. Lealdade (carta do repórter). In: LIMA, V. (org.). A Mídia nas Eleições de 2006. São Paulo: Editora Fundação Perseu Abramo, 2007.

ZALLER, J. R. The Nature and Origins of Mass Opinion. Cambridge: University Press, 1992.

ZALLER, J. R.; PRICE, V. "Who Gets the News? Alternative Measures of News Reception and Their Implications For Research". Public Opinion Quarterly, vol. 57, p. 133-164, 1993.

ZUCCO, C. "The President's 'New' Constituency: Lula and the Pragmatic Vote in Brazil's 2006 Presidential Election". Journal of Latin American Studies, vol. 40, p. 29-49, 2008.

\section{Apêndice: descrição das variáveis}

Presidente $1^{\circ}$ turno 2010. Pergunta 42 do questionário (Em quem o Sr.[a] votou para presidente no primeiro turno?), codificada: $1=$ Dilma, $2=$ Serra, $3=$ Marina e 4 = Outros/Não Voto (Brancos, Nulos e Abstenções).

Presidente $2^{\circ}$ turno 2010. Pergunta 47B do questionário (Em quem o Sr.[a] votou para presidente no segundo turno?), codificada: $1=$ Dilma, 2 = Serra e $3=$ Não Voto (Brancos, Nulos e Abstenções).

Presidente $1^{\circ}$ turno 2006. Pergunta 74 do questionário (Em quem o Sr.[a] votou no primeiro turno da eleição presidencial de 2006?), codificada: 1 = Lula, 2 = Alckmin, 3 = Outros e 4 = Não Voto (Brancos, Nulos e Abstenções)..

Presidente $2^{\circ}$ turno. Pergunta 76 do questionário (E no segundo turno das eleições de 2006, em quem o Sr.[a] votou?), codificada: 1 = Lula, 2 = Alckmin e $3=$ Não Voto (Brancos, Nulos e Abstenções).

Índice de Atenção Política. Pergunta 88 do questionário (Vou ler para o Sr.[a] o nome de alguns políticos e gostaria de que me dissesse a qual partido eles são filiados. De qual partido é filiado?): $\mu=4,673 ; \sigma=3,253 ; \min .=0 ; \max .=17.0$ índice de atenção política utilizado nos modelos foi padronizado.

Jornal? Pergunta 100 do questionário (Quantos dias por semana o Sr.[a] lê jornal?), codificada: 1 = Nunca, $2=$ Raramente, $3=$ Um dia por semana, $4=$ Alguns dias por semana e $5=$ Todo dia.

Jornal Nacional. Pergunta 102 do questionário (Quantos dias por semana o Sr.[a] assiste ao Jornal Nacional?), codificada: $1=$ Nunca, $2=$ Raramente, $3=$ Um 
dia, 4 Dois dias, 5 = Três dias, 6 = Quatro dias, $7=$ Cinco dias e $8=$ Todo dia.

Datena (Brasil Urgente). Pergunta 103 do questionário (E o programa Brasil Urgente, da Band, apresentado por José Luiz Datena, quantos dias por semana o Sr.[a] assiste?), codificada: 1 = Nunca, 2 = Raramente, $3=$ Um dia, 4 Dois dias, $5=$ Três dias, 6 = Quatro dias, $7=$ Cinco dias e 8 = Todo dia.

Debates. Pergunta 104 do questionário (E os debates entre os candidatos a presidente, o Sr.[a] assistiu?), codificada: 1 = Não, 2 = alguns e $3=$ todos.

Avaliação do presidente Lula. Pergunta 21 do questionário (Na sua opinião, de maneira geral o governo Lula nos últimos 4 anos foi), codificada: $1=$ Péssimo, $2=$ Ruim, 3 = Bom e 4 = Ótimo.

PT: partido preferido. Pergunta 23 do questionário (Qual é o partido que melhor representa a maneira como o Sr.[a] pensa?), codificada: $1=\mathrm{PT}, 0=$ Outros/Nenhum.

PSDB: partido preferido (idem): 1 = PSDB, $0=$ Outros/Nenhum.

PV: partido preferido (idem): 1 = PV, $0=$ Outros $/$ Nenhum.

Avaliação econômica do país. Pergunta 109 do questionário (Sr.[a] considera que a situação econômica atual do país está igual, melhor ou pior do que há 12 meses?), codificada: 1 = Pior, 2 = Igual, 3 =Melhor.

Avaliação econômica do pessoal. Pergunta 111 do questionário (Sr.[a] acha que a sua atual a situação econômica está igual, melhor ou pior do que há 12 meses?), codificada: 1 = Pior, 2 = Igual, 3 =Melhor.

Bolsa Família. Pergunta 114 do questionário (O[a] Sr.[Sra.] participa do programa , do governo federal?), codificada: $1=\operatorname{Sim}, 0=$ Não.

Sexo: 1 = Homem, $0=$ Mulher.

Idade: $1=16$ a $24,2=25$ a $34,3=35$ a $44,4=45$ a 60 e $5=$ Acima de 60.

Escola: $1=$ Ate $4^{\mathrm{a}}$ série, $2=5^{\mathrm{a}}$ a $8^{\mathrm{a}}, 3=2^{\circ}$ Grau e $4=$ Superior.

Renda familiar mensal: $1=$ Até $2 \mathrm{SM}, 2$ = de 2 a $5 \mathrm{SM}, 3=$ de 5 a $10 \mathrm{SM}$ e $4=$ Acima de $10 \mathrm{SM}$.

CO/SUL: 1 = Centro-Oeste/Sul, 2 = Outras.

NO/NE: 1 = Norte/Nordeste, 2 = Outras.

Heloisa Bezerra - diasbezerra.h@gmail.com

Pedro Mundim - psmundim@yahoo.com.br

Recebido para publicação em setembro de 2011. Aprovado para publicação em outubro de 2011. 